\title{
Asymmetric Impact of Crude Oil Cost on Diesel Price in Canada: Evidence from Nonlinear ARDL Model
}

\author{
Fidelia N. Onuigbo ${ }^{1} \quad$ Jonathan E. Ogbuabor $^{2 *}$ \\ 1.Department of Economics, Enugu State University of Science and Technology (ESUT), Enugu, Nigeria \\ 2.Department of Economics, University of Nigeria, Nsukka, Nigeria
}

\begin{abstract}
This paper examined the retail diesel market in Canada for evidence of asymmetric price adjustment and rentseeking arising from the fluctuations in crude oil prices over the period January 2005 to December 2015. The study used the recently introduced nonlinear ARDL model. The findings indicate sluggish speed of adjustment of $22 \%$ for both ex-tax prices and pump prices, which is typical of markets witnessing weak competition and prolonged periods of mispricing. However, the results further indicate that Canadian consumers of retail automotive diesel are sufficiently insulated from the fluctuations of the international crude oil market since the estimated long-run coefficients ranged between 0.60 and 0.69 . At the $5 \%$ level, the results did not show significant evidence of long run asymmetry in the retail diesel market. In addition, the results did not indicate significant short run additive asymmetry at the $5 \%$ level or the prevalence of the rockets and feathers effect. The absence of the rockets and feathers effect also means that the market is free from the problem of rent-seeking by retailers. This is desirable and indicates that regulatory policies should continuously monitor the market in order to preserve competition and the overall social welfare.
\end{abstract}

Keywords: Asymmetric Price Adjustment, Rockets and Feathers Effect, Nonlinear ARDL Model, Canada.

JEL Codes: Q43; D40; C22; N12

DOI: $10.7176 / \mathrm{JESD} / 10-4-14$

\section{Introduction}

Canada is an oil-rich country. According to International Energy Agency statistics (http//www.iea.org/stastistics/), it is the World's $5^{\text {th }}$ largest oil producer and a key oil exporter. Most of its oil exports go to the United States, owing to the proximity between the two countries and their long standing trade relations. Nonetheless, the recent fluctuations in crude oil prices across the globe which started in 2013 have rekindled the interest of researchers on the transmission of crude oil price changes to the prices of petroleum products. Consumers across the globe are concerned that the recent decline in oil prices is not being felt by consumers of petroleum products at the pumps, even in oil rich countries like Canada. An important question becomes: does Canadian automotive diesel market respond symmetrically or asymmetrically to changes in crude oil prices? This study investigates this question. In addition, this study also examines whether the Canadian retail automotive diesel market is fraught with the problem of rent-seeking or otherwise.

Crude oil is the main input in the production of petroleum products including diesel, and asymmetric pattern of price transmission from crude oil market to retail energy markets has become a major feature of the global energy sector. For example, Data from the monthly oil price statistics of International Energy Agency (IEA) indicate that average cost of imported crude oil in the United States (U.S) declined from 103.14 U.S dollars per barrel in August 2013 to 99.51 US dollars per barrel in June 2014 (the IEA provides monthly price statistics for crude oil, gasoline, diesel, domestic heating oil and industrial fuel oil for selected countries in the global economy at $\mathrm{http} / \mathrm{www}$.iea.org/stastistics/topics/pricesandtaxes). However, the IEA statistics also indicate that the average retail price of gasoline at pump increased from 0.94 US dollars per litre in August 2013 to 0.98 US dollars per litre in June 2014. By December 2015, the cost of imported crude in the U.S had declined to 33.37 US dollars per barrel while the retail price of gasoline declined only marginally to 0.54 US dollars per litre. In the United Kingdom (UK), the average cost of imported crude oil declined massively from 135.44 US dollars per barrel in July, 2008 to 41.78 US dollars per barrel in January, 2009, while the average retail price of gasoline declined only marginally from 1.19 pounds per litre to 0.90 pounds per litre respectively. Again, the average cost of imported crude oil in the UK declined drastically from 128.14 US dollars per barrel in March 2012 to 51.61 US dollars per barrel in January, 2015, while the retail prices of gasoline only declined marginally from 1.39 pounds per litre to 1.10 pounds per litre respectively. Just like gasoline market, the retail price of diesel in the UK declined only marginally from 1.21 pounds per litre in March 2012 to 0.96 pounds per litre in January, 2015.

According to Bacon (1991), Borenstein, Cameron and Gilbert (1997, henceforth BCG), and GreenwoodNimmo and Shin (2013, henceforth GS13), such asymmetric pattern of retail price adjustment is typical of markets witnessing practices that are detrimental to consumers' welfare, such as rent seeking, uncompetitive pricing, collusion, product hoarding and artificial shortage/scarcity of the products, among others. The UK Monopolies and Mergers Commission (MMC) between 1965 and 1990 concluded that there was evidence of asymmetric response of gasoline price to changes in crude oil cost. The MMC suggested that when faced with rising input 
costs, sellers rapidly adjust prices upwards; but when they are faced with decreasing costs, they adjust prices downwards very sluggishly. The MMC termed this pattern of asymmetric price adjustment 'rockets and feathers' (MMC, 1965, 1979, 1990). Bacon (1991) econometrically established the reality of asymmetric price transmission from crude oil market to retail gasoline market as well as the prevalence of the rockets and feathers effect in the UK retail gasoline market.

The nature of market failure accompanying this pattern of asymmetric price adjustment motivated the interest to investigate econometrically the Canadian retail diesel market for evidence of asymmetric price adjustment and possibility of rent-seeking. This will expose the happenings in the market and help in regulating the operations of the market to the benefit and growth of the Canadian economy.

\section{An overview of the empirical literature}

Some studies in the literature have empirically investigated the problem of asymmetric adjustment of retail energy prices following changes in crude oil costs using various methodologies. While some of these studies have found evidence in support of the hypothesized asymmetric response of retail energy prices to changes in crude oil costs, others did not find any evidence of such asymmetry. However, most of the studies did not focus on the issue of rent-seeking. This study fills this gap in the Canadian diesel market. In what follows, some of the empirics are discussed.

Chacra (2002) examined the effects of global energy price shocks on retail energy prices in Canada. More specifically, the study examined the response of the consumer price indexes for gasoline, heating oil, natural gas, and electricity in Canada to movements in world crude oil prices, using an error correction framework. The results indicate that the forecasting ability of error-correction models outperform that of competing auto regressive and random-walk models. The study further finds that even though prices at the retail level are determined by input costs, industry dynamics, and in some cases, by government regulation; the adjustment process of downstream prices indicate that government regulation leads to a sluggish adjustment process, as seen in the retail natural gas and electricity markets. Though the study did not carry out an indepth micro-analysis, it does appear that in some sectors with strong competition, the response of retail prices to oil price shocks seems to be more spread overtime, as in the case of heating oil. All in all, the findings of Chacra (2002) are consistent with the hypothesized asymmetry.

Chen, Finney and Lai (2005) provide new supportive evidence for asymmetric adjustment in U.S retail gasoline prices. The asymmetric transmission is found to occur not just through the spot markets of crude oil and refinery gasoline but also through their future markets. The study further shows that the observed asymmetry in price transmission primarily occurs downstream, not upstream, of the transmission process. Grasso and Manera (2007) studied the gasoline markets of France, Germany, Italy, Spain and UK over the period 1985 to 2003 using asymmetric ECM, autoregressive threshold ECM and ECM with threshold cointegration. The results indicate that all the models captured some evidence of asymmetric behavior.

GS13 used the nonlinear ARDL framework to examine the UK gasoline, diesel, kerosene and gas oil markets over the period January 1999 to March 2013. They found evidence in support of the presumed asymmetry, which is largely obscured at pump where prices include both tax and duty suggesting the possibility of firms using tax system to conceal rent-seeking behavior. Atil, Lahiani and Nguyen (2014) used the recently developed nonlinear autoregressive distributed lags (NARDL) model to examine the pass-through of crude oil prices into gasoline and natural gas prices. This approach allowed the study to simultaneously test the short-and-long-run non-linearities through positive and negative partial sum decompositions of the predetermined explanatory variables. It also offers the possibility to quantify the respective responses of gasoline and natural gas prices to positive and negative oil prices affect gasoline price and natural gas prices in an asymmetric and nonlinear manner, but the price transmission mechanism is not the same.

Bastianin, Galeotti and Manera (2014) observed that even though there have been many contributions documenting that downstream prices are more reactive to increases than to decreases in upstream prices, little is known about the forecasting performance of economic models incorporating asymmetric price transmission from crude oil to gasoline. The study compared point, sign and probability forecasts from a variety of Asymmetric ECM (A-ECM) and Threshold Autoregressive ECM (TAR-ECM) specifications against a standard ECM. The study show that the rockets and feathers hypothesis (RFH) is useless for point forecasting while it can be explained to produce more accurate sign and probability forecasts. It also highlighted that the forecasting performance of the estimated models is time-varying. Pal and Mitra (2015) used a multiple threshold nonlinear autoregressive distributed lag model to assess the non linear relationship among crude oil and petroleum product prices in the United States. The contribution of the study is in splitting the crude price fluctuation in multiple partial sum series, which allows for a more detailed and minute analysis of the relationship. Apart from confirmation of nonlinear influences, the study also found the presence of a relatively high asymmetric impact at the lower crude oil prices.

Chen, Huang and Ma (2017) employed an asymmetric error-correction model (AECM), monthly data on wholesale prices of gasoline and diesel products in China, and international crude oil prices for February 2006 to 
October 2013 to examine whether China's gasoline and diesel prices adjust asymmetrically to international crude oil price changes. The empirical results suggest that increases and decreases in international oil prices have asymmetric effects on both wholesale prices of gasoline and diesel fuel in China, and that both increases and decreases in international oil prices have a greater effect on diesel prices than on gasoline prices in China. If there is no change in the maximum retail price, the asymmetry results from the transmission of wholesale prices in China with international oil prices. However, if there is a change in maximum retail prices, both international oil prices and maximum retail prices cause the asymmetry.

Karagiannis Panagopoulos and Vlamis (2015) studied the nature of price adjustment in the gasoline markets of Germany, France, Italy and Spain. The study examined whether crude oil costs are transmitted to retail gasoline prices in the short and long-run, and tested the symmetry of price adjustment hypothesis. An Error Correction Model, which accounts for possible asymmetric adjustment behavior, was applied for the estimation of the international crude oil price pass-through and testing of the symmetric /asymmetric nature of the retail fuel price adjustments in these economies. The results show that rigidities in the transmission process exist but the retail fuel speed of upward/downward price adjustment to equilibrium is considered as symmetric in all four economies analyzed. Thus, the findings on the whole do not provide firm evidence to support the rockets and feathers hypothesis that crude oil price increases are passed along to the retail customer more fully than the crude oil price decreases. Honarva (2009) used Crouching ECM approach to investigate the US retail gasoline market. The results are consistent with Bachmeir and Griffin (2003), which found that there is no evidence of rockets and feathers effect in the US gasoline market.

The foregoing overview of the empirical literature on the symmetric/asymmetric relationship between crude oil costs and retail energy prices indicates that important gaps still exist towards a more comprehensive understanding of this relationship. First, the studies reviewed are yet to explicitly investigate the Canadian diesel market for the possibility of retail firms manipulating the tax system to conceal rent-seeking behavior. Among these studies, only GS13 has investigated this possibility for the UK retail energy markets. However, the foregoing empirical literature review shows that no consensus has been reached regarding the nature and existence of the rockets and feathers effect across various retail energy markets. This study contributes to this ongoing investigation.

\section{Data and methodology}

Monthly times series observations for the period 2005M1 to 2015M12 (a total of 132 observations) constitute the data for this study. Retail prices of Canadian diesel both at pump (i.e inclusive of tax and duty) and ex-tax (i.e. exclusive of tax and duty) and the costs of imported crude oil in Canada are used. This study used the crude oil cost for Canada measured in dollars per barrel to effectively track the asymmetry in the response of change in the retail price of diesel to change in the cost of crude oil. The retail price of diesel measured in the Canadian national currency was converted to U.S dollars using the exchange rate data obtained from OECD statistics (monthly monetary and Financial Statistics MEI). The entire data is indexed to year $2010(2010 \mathrm{Y}=100 \%)$ and logged prior to estimation. The data were sourced from the International Energy Agency (IEA) Monthly Oil Price Statistics. Figure 1 shows the time series plot of the data before it was logged for estimation. The plot shows that the retail diesel prices and the crude oil costs in Canada track themselves very closely, contrary to the presumed asymmetry. The close comovement between the variables also suggests that the variables may have a stable long-run relationship. This study will empirically examine the existence of this long-run relationship using the bounds testing approach of Pesaran, Smith and Shin 2001 (henceforth PSS) and the t-BDM statistic of Banajee et al (1998). 
Figure 1: Time series plot of the data

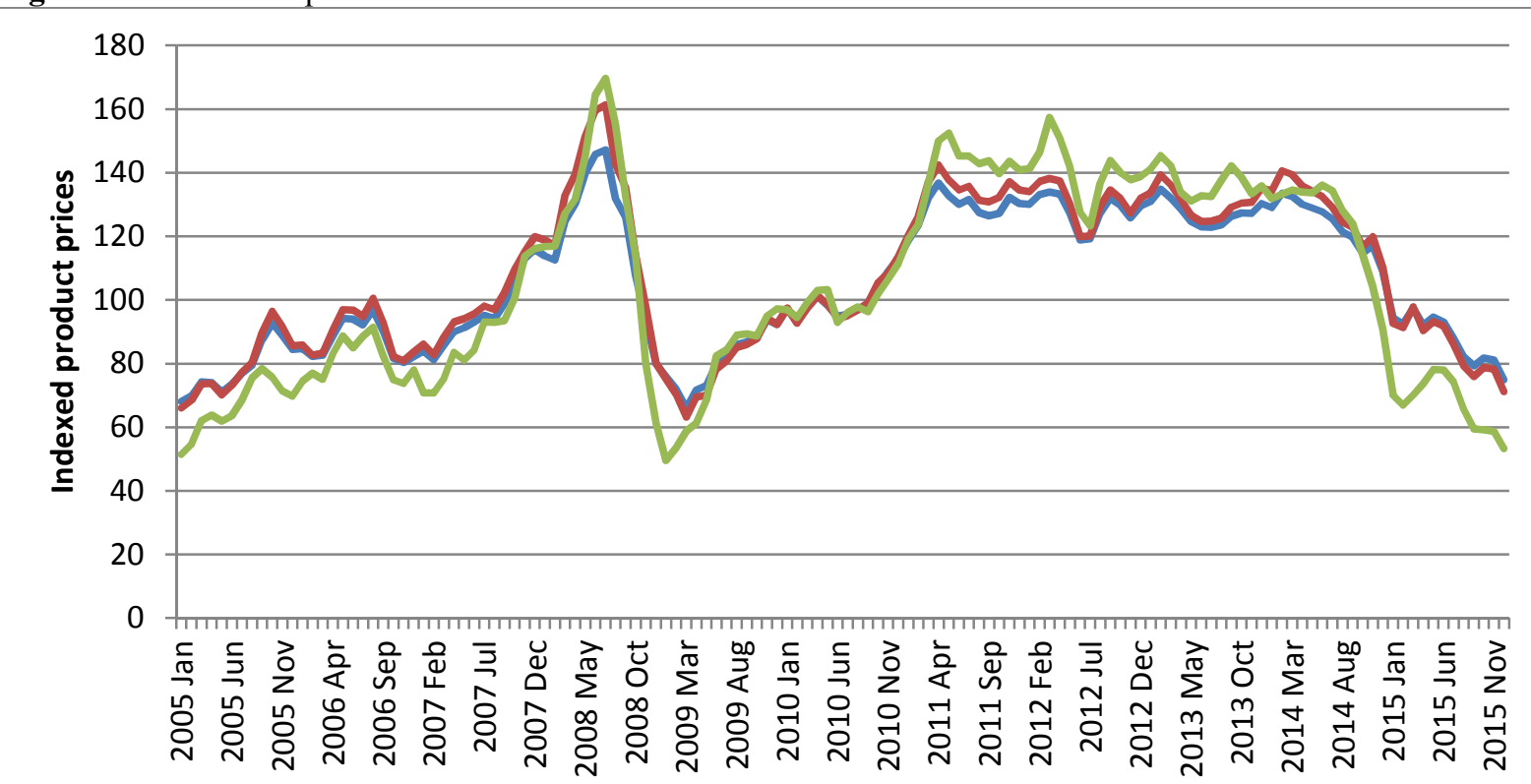

Dates

DieselPump $\longrightarrow$ DieselExTax CrudeOil

Source: Authors. Note: This plot is based on the indexed representation of the data before it was logged for estimation.

The study adopted the econometric framework applied by GS13 in modeling the asymmetric price transmission in the UK retail energy sector, which was initially advanced by Shin, Yu and Greenwood-Nimmo (2013) for modeling asymmetric cointegration and dynamic multipliers in a non-linear autoregressive distributed lag (NARDL) framework. Under this framework, short-run and long-run non-linearities were introduced through positive and negative partial sum decompositions of the explanatory variables.

The framework is built around the asymmetric cointegrating relationship of the form:

$Y_{t}=\theta^{+} X_{t}^{+}+\theta^{-} X^{-}+u_{t}$

Where $Y_{t}$ is an I(1) variable, and the explanatory variable is decomposed as follows:-

$X_{t=} X_{0}+X_{t+}^{+} X_{t}^{-}$

Where $X_{t=}^{+} \sum_{j=1}^{t} \max \left(\Delta \mathrm{x}_{\mathrm{j}}, 0\right)$ and $X_{t}^{-}=\sum_{j=1}^{t} \min \left(\Delta \mathrm{x}_{\mathrm{j}}, 0\right)$ are partial sum processes of positive and negative changes in $X_{t}$, while $X_{0}$ is an initial threshold value that is assumed to be zero following Shin, $\mathrm{Yu}$ and Greenwood-Nimmo (2013). $\Delta$ is the first difference operator while $\theta^{+}$and $\theta^{-}$are the associated asymmetric long-run parameters. The NARDL $(p, q)$ model associated with equation (1) can be written in its level form as follows:

$$
\left.Y_{t}=\sum_{j=1}^{P} \phi_{\mathrm{j}} \mathrm{Y}_{\mathrm{t}-\mathrm{j}+} \sum_{j=O}^{q}{ }_{\left(\theta_{\mathrm{j}}^{+}\right.} X_{t-j+\theta^{j}}^{-} X_{t-j}^{-}\right)+\varepsilon_{\mathrm{t}}
$$

The underlying model in this study is derived from equation (3) following Shin, Yu and Greenwood-Nimmo (2013). This is specified in its error correction form as follows:

$\left.\Delta \mathrm{Y}_{\mathrm{t}}=\rho \mathrm{Y}_{\mathrm{t}-1}+\theta^{+} X_{t-1+\theta^{-}}^{+} X_{t-1}^{-} \sum_{j=1}^{p-1} \phi_{\mathrm{j}} \Delta \mathrm{Y}_{\mathrm{t}-1}+\sum_{j=O}^{q-1}{ }_{\left(\Omega^{j}{ }_{\Delta}^{+1}\right.} X_{t=1+Л^{j}}^{+1}{ }_{\Delta}^{-} X_{t-1}^{-}\right)$

$+\varepsilon_{\mathrm{t}}$

Where $\rho$ is the speed of adjustment while $\beta^{+}=\frac{-\theta^{+}}{\rho}$ and $\beta^{-}=\frac{-\theta^{-}}{\rho}$ are the asymmetric long-run parameters.

In the above specifications, $\mathrm{Y}_{\mathrm{t}}$ captures the retail price of diesel in Canada, while $\mathrm{X}_{\mathrm{t}}$ captures the crude oil costs for Canada. To ascertain the orders of integration of the variables in this study, the ADF unit root tests were 
used. This is to ensure that they are consistent with the underlying requirements of the nonlinear ARDL framework. The result of cointegration tests based on the bounds testing approach of Pesaran, Smith and Shin 2001 (henceforth PSS) and the t-BDM statistic of Banajee et al (1998) are also reported in this study.

\section{Empirical results and discussion}

The time series properties of the data were examined using the ADF unit root tests. The results are presented in Table 1.

Table 1: ADF Unit Root Test Results

\begin{tabular}{|l|l|l|l|l|}
\hline Variables & $\begin{array}{c}\text { Test 5\% Critical } \\
\text { Value }\end{array}$ & $\begin{array}{c}\text { Level } \\
\text { ADF Test Stat }\end{array}$ & $\begin{array}{c}\mathbf{1}^{\text {st }} \text { Difference ADF } \\
\text { Test Stat }\end{array}$ & $\begin{array}{c}\text { Order of } \\
\text { Integration }\end{array}$ \\
\hline Diesel at Pump & -3.445 & -1.679 & $-7.076^{*}$ & $\mathrm{I}(1)$ \\
\hline Diesel Ex-Tax & -3.445 & -1.717 & $-7.353^{*}$ & $\mathrm{I}(1)$ \\
\hline Crude Oil & -3.445 & -2.186 & $-5.999^{*}$ & $\mathrm{I}(1)$ \\
\hline
\end{tabular}

Source: Authors. Notes: Diesel at pump denotes the retail diesel prices which are inclusive of tax and duty; while Diesel Ex-Tax denotes the ex-tax prices of diesel. *denotes significance at 5\% level.

The results in Table 1 shows that the variables are integrated of order one, I(1). This shows that there may be an equilibrium relationship between the variables. Also, the results of the cointegration tests based on the PSS bounds tests and the t-BDM statistic of Banarjee et al (1998) are also reported in Table 2 together with the nonlinear ARDL estimation results based on equation (4). The cointegration test results indicate the existence of a stable long-run relationship between the retail prices and the costs of crude oil.

Let us now focus on the results in Table 2, which shows the response of diesel prices at pump and ex-tax to changes in crude oil cost. The results indicate very sluggish speed of adjustment of $22 \%$ per month at pump and ex-tax price. This is similar to the pattern of sluggish speed of adjustment found by GS13 in the UK retail petroleum products markets. This is typical of markets witnessing weak competition and prolonged periods of mispricing. However, we do not find any significant evidence of long-run asymmetry in the diesel markets since the estimated positive long run coefficients (i.e the $\beta^{+} \mathrm{s}$ ) are not statistically significantly different from their corresponding negative ones (i.e. the $\beta^{-} \mathrm{s}$ ). The Canadian diesel long-run estimated coefficients which range between 0.60 and 0.69 suggests that Canadian consumers of retail automotive diesel are sufficiently protected from the fluctuations of the international crude oil market.

The results indicate a significant short-run additive asymmetry in diesel market only at the $10 \%$ level. Interestingly, however, the patterns of this asymmetry are not consistent with rockets and feathers effect because the sum of positive short-run parameters (which is 0.38 ) in the ex-tax model is less than the sum of the corresponding negative short-run parameters (which is 0.67). A similar pattern is also observed in the pump price model. Note that while the positive short-run parameters captures the response of retail energy prices to increases in crude oil costs, the sum of the negative short-run parameters also captures the response to crude oil price decreases. Hence the pattern of asymmetry for both the ex-tax prices and the pump prices show that there is no evidence of the rockets and feathers effect. Obviously, the absence of the rockets and feathers effect in the Canadian retail diesel market implies that this market does not have the problem of rent-seeking by retailers. In other words, the results indicate that there is no likelihood of manipulating the tax system to conceal rent-seeking behaviours by retail firms. 
Table 2: NARDL Estimation Results

\begin{tabular}{|c|c|c|}
\hline Dependent variables & Diesel (Ex-Tax Price) & Diesel (Pump Prices) \\
\hline \multicolumn{3}{|l|}{ Estimated Coefficients } \\
\hline$\rho$ & $-0.22 * * *$ & $-0.22 * * *$ \\
\hline$\beta^{+}$ & $0.69 * * *$ & $0.61 * * *$ \\
\hline$\beta^{-}$ & $0.69 * * *$ & $0.60 * * *$ \\
\hline$\sum_{j=1}^{q-1} \pi^{j}$ & $0.38 * * *$ & $0.35 * *$ \\
\hline$\sum_{j=1}^{q-1} \bar{Л}^{j}$ & $0.67 * *$ & $0.59 * *$ \\
\hline \multicolumn{3}{|l|}{ Symmetry Tests } \\
\hline $\mathrm{Ho}=\beta^{+}=\beta^{-}$ & 0.08 & 0.94 \\
\hline Ho $=\sum_{j=1}^{q-1} \pi^{j}=\sum_{j=1}^{q-1} \pi^{j}$ & $2.88 *$ & $2.78 *$ \\
\hline \multicolumn{3}{|l|}{ Diagnostic Checks } \\
\hline$F_{\text {PSS }}$ & $5.54 *$ & $5.64^{*}$ \\
\hline$t_{\mathrm{BDM}}$ & $-3.95 * * *$ & $-3.95 * * *$ \\
\hline BG Test $\left(\mathrm{NR}^{2}\right)$ & 12.86 & 11.94 \\
\hline ARCH Test & 9.46 & $21.39 * *$ \\
\hline Adjusted $\mathrm{R}^{2}$ & 0.64 & 0.65 \\
\hline
\end{tabular}

Source: Authors. Notes: Diesel Ex-tax denote the ex-tax retail prices of diesel while Diesel pump prices denote the retail prices (i.e inclusive of tax and duty). The notations for the estimated coefficients relate to the nonlinear ARDL model of equation (4). The reported symmetry tests are standard Wald tests. The Breusch-Godfrey serial correlation test is the BG Test while the ARCH Test is the standard Heteroskedasticity Test. Since the dataset comprises monthly series, the BG Test and the ARCH Test were conducted at lag 12 . The relevant $\mathrm{K}=1 \mathrm{critical}$ values reported by PSS for the $\mathrm{t}_{\mathrm{BDM}}$ statistic are $-2.91,-3.22$, and -3.82 at the $10 \%, 5 \%$ and $1 \%$ levels. The equivalent critical values for the $\mathrm{F}_{\mathrm{PSS}}$ statistic are 4.78, 5.73 and 7.84 . *denotes significance at the $10 \%$ level; $* *$ denotes significance at the $5 \%$ level; ***denotes significance at the $1 \%$ levels.

This study did not find significant evidence of the rockets and feathers effect or rent-seeking behavior in the Canadian retail diesel markets. The diagnostic checks also indicate that the assumptions of the underlying model have been adequately satisfied. Both the PSS bounds testing procedure and the $t_{\text {BDM }}$ statistic of Banerjee et al 1998 indicate the existence of stable equilibrium relationship between the variables, at least at the $10 \%$ level. The Breusch-Godfrey serial correlation tests indicate the absence of autocorrelation problem. At the 5\% level, the problem of heteroscedasticity is observed in the diesel market at pump. This was corrected using the Newey-West HAC method, but the patterns of the observed asymmetry did not change. This is not surprising because the least squares estimator remains consistent in the presence of any patterns of autocorrelation and/or heteroscedasticity, even though the standard errors are no longer reliable. Finally, the adjusted $\mathrm{R}^{2}$ indicate that changes in crude oil costs account substantially for variations in the retail diesel markets (this ranged between 64\% - 65\%). This goes to support the fact that crude oil is the main input material for the production of diesel.

\section{Conclusion and policy implications}

This paper reviewed the Canadian retail diesel market for asymmetric price adjustment and rent seeking following the recent ups and downs in the international crude oil prices. The study used the nonlinear autoregressive distributed lag (NARDL) model which was estimated in its error correction form to capture both long-run relationships and short-run dynamics. Monthly time series data for the period 2005M1-2015M12 were also used. The results indicate that the speed of adjustment is sluggish, which is typical of markets witnessing weak competition, extended periods of mispricing, and other collusive behavior that are detrimental to consumers' welfare. However, the result did not show significant evidence of long-run asymmetry, and that there is no evidence of the rockets and feathers effect in the Canadian retail diesel market. This implies that there is no problem of rentseeking by retailer firms in this market. Thus, the results indicate that there is no likelihood of manipulating the tax system to conceal rent-seeking behaviours by retail firms. These results are consistent with the dynamics of the oil industry in Canada, which show that the country is oil-rich with extensive pipeline facilities, refining capacity and other effective distribution networks. However, based on the finding of sluggish speed of adjustment, this study strongly recommends that policy makers and regulators in Canada should aim at continuously monitoring the retail diesel market in order to preserve competition and the overall social welfare are of the citizens. 


\section{References}

Atil, A., Lahiani, A. and D. K. Nguyen (2014). Asymmetric and nonlinear pass-through of crude oil prices to gasoline and natural gas prices. Energy Policy, 65(C), 567-573.

Bachmeier, L. J. and J. M. Griffin (2003). New Evidence on Asymmetric Gasoline Price Responses. The Review of Economics and Statistics 85(3), 772-776.

Bacon, R.W. (1991). Rockets and Feathers: The Asymmetric Speed of Adjustment of UK Retail Gasoline Prices to Cost Changes. Energy Economics 13, 211-218.

Banerjee, A., Dolado, J. and R. Mestre (1998). Error-correction Mechanism Tests for Cointegration in a Singleequation Framework. J. Time Ser. Anal. 19, 267-283.

Bastianin, A., Galeotti, M. and M. Manera (2014). Forecasting the oil-gasoline price relationship: should we care about the Rockets and the Feathers? Working Papers 269, University of Milano-Bicocca, Department of Economics.

Borenstein, S., Cameron, A.C. and R. Gilbert (1997). Do Gasoline Prices Respond Asymmetrically to Crude Oil Prices? Quarterly Journal of Economics 112, 305-339.

Chacra, M. (2002). Oil-Price Shocks and Retail Energy Prices in Canada. Working Paper 2002-38, Bank of Canada.

Chen, L., Finney, M. and K. S. Lai (2005). A threshold cointegration analysis of asymmetric price transmission from crude oil to gasoline prices. Economics Letters 89, 233 - 239.

Chen, Y., Huang, G. and L. Ma (2017). Rockets and feathers: The asymmetric effect between China's refined oil prices and international crude oil prices. Sustainability 9, 381 - 399. doi:10.3390/su9030381.

Grasso, M. and M. Manera (2007). Asymmetric Error Correction Models for the Oil-Gasoline Price Relationship. Energy Policy 35, 156-177.

Greenwood-Nimmo, M. and Y. Shin (2013). Taxation and the Asymmetric Adjustment of Selected Retail Energy Prices in the UK. Economics Letters 121, 411-416.

Honarvar, A. (2009). Asymmetry in Retail Gasoline and Crude Oil Price Movements in the United States: An Application of Hidden Cointegration Technique. Energy Economics 31(3), 395-402.

Karagiannis, S., Panagopoulos, Y. and P. Vlamis (2015). Are unleaded gasoline and diesel price adjustments symmetric? A comparison of the four largest EU retail fuel markets. Economic Modelling, 48(C), 281 - 291.

Monopolies and Mergers Commission (MMC) (1965). Report on the Supply of Petrol to Retailers in the United Kingdom, HMSO, London.

Monopolies and Mergers Commission (MMC) (1979). Report on the Supply of Petrol in the United Kingdom by Wholesale, HMSO, London.

Monopolies and Mergers Commission (MMC) (1990). The Supply of Petrol, HMSO, London.

Pal, D. and S. K. Mitra (2015). Asymmetric impact of crude price on oil product pricing in the United States: An application of multiple threshold nonlinear autoregressive distributed lag model. Economic Modelling, 51(C), 436-443.

Pesaran, M.H., Smith, R.J. and Y. Shin (2001). Bounds Testing Approaches to the Analysis of Level Relationships. Journal of Applied Econometrics 16, 289-326.

Shin, Y., Yu, B. and M. J. Greenwood-Nimmo (2013). Modelling Asymmetric Cointegration and Dynamic Multipliers in a Nonlinear ARDL framework, in: Horrace, W. C. and Sickles, R. C., eds., Festschrift in Honor of Peter Schmidt: Econometric Methods and Applications, Springer Science \& Business Media, New York. 